\title{
Behavioral Citation Analysis: Toward Collection Enhancement for Users
}

\author{
Beth E. Fuchs, Cristina M. Thomsen, Randolph G. \\ Bias, and Donald G. Davis Jr.
}

\begin{abstract}
A pilot study was developed to determine use of the University of Texas at Austin General Libraries' research collections in the fields of civil engineering and educational psychology and to investigate the research behavior of graduate students. First, the authors sampled bibliographic citations from dissertations completed during the years 1997 and 2002 in the above-named fields. Then, a survey was sent to the dissertation writers to gain insight into use and opinions of library services for their graduate research. Analysis of information provided by both collectionand user-centered data-gathering techniques serves to underscore the value of the merged evaluation methods.
\end{abstract}

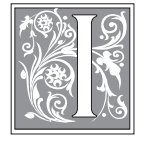

ncreasing journal and monograph costs juxtaposed with flattening appropriations have placed academic library collection development staffs in the midst of a dilemma: How can libraries provide enhanced services from diminishing resources and, at the same time, protect the quality of research materials provided to users? Librarians address this question in several ways, one being to gather information on usage and utility of the library's collection as a way to focus selection and perhaps digitization of additional materials to better meet the needs of constituents. Collection evaluation techniques, whether they provide data on the collection or on the user, generate information that can be integrated into a larger evaluation effort to help reshape the institution's vision. ${ }^{1-4}$

The researchers set out to gather and then integrate qualitative and quantitative data on collection use by merging the results of two evaluation methods characterized as a "behavioral citation analysis," an enhanced citation analysis combining a traditional citation analysis with parallel behavioral (survey) data. Within the larger framework of information needs assessment, citation analysis offers a well-documented method for gathering data on the utility of a collection. Early use of bibliographic citations as a means of evaluating library holdings against other libraries' collections extends

Beth E. Fuchs is a Reference and Electronic Resources Librarian in Reeves Library at Moravian College $\mathcal{E}$ Moravian Theological Seminary; e-mail: fuchsb@moravian.edu. Cristina M. Thomsen is the Library Director in Chan Shun Centennial Library at Southwestern Adventist University; e-mail: thomsen@swau.edu.Randolph G. Bias is an Associate Professor in the School of Information and the Director of the Information Experience Lab at the University of Texas at Austin; e-mail: rbias@ischool.utexas.edu. Donald G. Davis Jr. is Professor Emeritus of Library History in the School of Information and Department of History at the University of Texas at Austin; e-mail: dgdavis@ischool.utexas.edu. The research was conducted May-August 2004 when Fuchs and Thomsen were students in the School of Information at the University of Texas, Austin. 
back to the work of Charles Coffin Jewett, in $1848 .{ }^{5}$ More recently, citation analysis has been used to identify significant authors in a field, core lists of journals and monographs for a subject, and publishers of influence. ${ }^{6-8}$ For academic research libraries, dissertations offer a particularly fertile resource for bibliographic citation analysis, primarily because they represent in-depth investigations into particular research questions. Dissertation bibliographies are of considerable value to subject specialists in libraries charged with collection maintenance and indicate research trends of which academic libraries should be aware.

This project began as a pilot study to assist the University of Texas at Austin Libraries' Collection and Information Resources Department (CIRD) in assessing its research collections' utility. The time period chosen for this study, 1997 to 2002, coincides with two significant changes in service provided by UT Libraries: the arrival of electronically accessible full-text resources, and budget decreases that necessitated a reduction in paper-based serials and monograph acquisitions. The question of utility and perceived utility of the research collection is accorded particular significance when libraries are inundated with changing expectations by users, triggered by technological options that did not exist a decade ago for accessing resources.

The researchers recognized, however, that a traditional citation analysis requires much inference on the part of the researchers and those in charge of library collections. By deciding to supplement the citation analysis with survey data on information-seeking behavior collected from the dissertation authors, the study aimed to probe deeper into the authors' experiences, needs, and wishes.

\section{Review of Literature}

According to Anne L. Buchanan and Jean-Peirre V. M. Herubel, bibliographic citation analysis of dissertations offers an unparalleled means of learning the ex- tent and completeness of an institution's library research collection. These bibliographies contain a wealth of information resources vital for creating disciplinespecific subject guides that ensure comprehensive coverage. ${ }^{9}$ In 1978, Elizabeth Pan concluded that citation studies are reliable indicators of resource use in libraries. ${ }^{10}$ More recently, Margaret Stieg Dalton and Laurie Charnigo describe the study of "information-seeking behavior" as populated by thousands of reports, primarily created in the 1990s and forward..$^{11}$ The importance of examining the information needs of graduate students as a distinct user population is frequently addressed in the professional literature. ${ }^{12-}$ ${ }^{13}$ Couching citation analysis not only in traditional terms of resource use but also in information needs and behavior seemed a fruitful path to pursue.

William L. Emerson published one of the earliest uses of student bibliographies to assess collection value in 1957 . He examined the bibliographies of twentythree engineering dissertations written by students at Columbia University and then checked them against Columbia's collection to determine its adequacy in supporting academic research. The study's basic assumption, one currently taken for granted in citation studies, was that items listed in the dissertations' bibliographies revealed the materials used by students. ${ }^{14}$

Citation analysis also has been used to recommend materials for selection and deselection. Joy Thomas observed psychology graduate students at California State University, Long Beach, from 1981 to 1990 , and created a profile of library resource use generated from the results of a thesis citation project. This work, undertaken as part of a collection evaluation effort to identify journals that could be canceled with limited repercussions, demonstrated that the students depended heavily on the local collection for their citations (91.9\%), with the remainder coming through interlibrary loan or some other means of access. ${ }^{15}$ Graduate stu- 
dent citation analysis thus provided the library staff not only with materials used but also with substantive information to bolster recommendations for continuance or discontinuance of specific titles, on the basis of a comprehensive survey of student research.

Citation analyses of theses and dissertations are conducted most frequently within a single institution as a means of assessing the collection utility of the library system at that particular college or university. Lois Kuyper-Rushing described a different form of citation analysis, in which the graduate papers of multiple universities are analyzed and then shaped into core lists for specific disciplines, thus transcending the focused interests of individual institutions. ${ }^{16}$ The advantage of this type of citation study is that individual institutions can then compare their resources and usage with national data for a more thorough evaluation of their program.

Although citation analysis provides one means of evaluating the utility of a library's research collection, additional techniques are increasingly seen as a necessary part of a comprehensive evaluation. In a recent publication, Laurel A. Haycock offered several caveats in using citation analysis to determine a library research collection's adequacy. Among them, limited student research skills might reflect an incomplete understanding of the extent of available library resources, and graduate students might choose readily available local materials over more important material not locally held, threatening self-perpetuating mediocrity. ${ }^{17}$ Margaret Sylvia and Marcella Lesher described the results of a thesis reference analysis extracted from psychology and counseling theses during a six-year period. By adding a shelving count that tracked psychology journals' in-library use as well as a cost-effectiveness measure that compared use in theses with subscription costs, the authors created a data-driven proposal for journal selection. ${ }^{18}$
In studying the information-seeking behavior of humanities scholars in 1975, Lois Bebout, Donald G. Davis Jr., and Donald Oehlerts recognized that citation analysis had been carried out for a few academic disciplines and proposed that large-scale surveys also should be conducted, consisting of questionnaires and interviews to better focus library collection development in the humanities. The authors noted that a large-scale English program of evaluating resource use in the social sciences, INFROSS (Information Requirements of Social Scientists), modeled such a survey. ${ }^{19}$ This effort consisted of surveying, interviewing, and observing researchers regarding their preferred research venues, types of information used (e.g., historical, statistical), physical forms and other channels of information (e.g., periodicals, monographs, theses), and methods used to locate information. ${ }^{20}$

Recent interest has turned toward studying the impact of full-text electronic resources on the needs and research behaviors of library users. A study conducted to identify the use and impact of electronically accessible journals demonstrated that the availability of online materials had changed the research patterns of Yale University scholars between the years 1991 and 2001. Mean and median age of bibliographic citations dropped in the more recent articles, prompting the researchers to speculate that scholars are becoming less inclined to use (and therefore cite) classic monographs or research sources. ${ }^{21}$

The UT Libraries were well aware of the trend toward use of electronic resources and were interested in studying how resource use has changed since the broad availability of the Internet and the online full-text library. ${ }^{22}$ In setting out to conduct this analysis, the researchers agreed with Haycock that a citation analysis alone might miss important information about motivations for use of certain citations. Rather than employ a large-scale, broadcast survey as suggested by Bebout et al., ${ }^{23}$ the researchers 
employed a focused survey of the author cohorts whose dissertations provided the citations for analysis.

\section{Method}

The present study of the research collection at the University of Texas at Austin Libraries consisted of two evaluative components: one was collection-centered and the other, user-centered. The first part, a classic bibliographic citation analysis, consisted of sampling dissertations from four academic cohorts: civil engineering (CE) and educational psychology (EP), each for 1997 and 2002. These disciplines offered a contrast in resource use by graduate students in the applied sciences and in the behavioral sciences, according to information-seeking behavior studies of the groups. ${ }^{24}$ The programs also produced sufficient graduates in each year to provide a meaningful study population. The year 2002 was the most current year for which UT dissertations were available to the researchers, and the earlier cohort, 1997, reflects a time prior to extensive access to electronic full-text resources, spanning a period of substantial change in the UT Austin Libraries' budget and acquisitions.

\section{Dissertation Bibliographic Citation Analysis}

Twenty-six dissertations were selected from the total population for each cohort, which ranged in number from 26 to 34 . The smallest number of dissertations per chosen discipline per year was 26, for educational psychology for 1997. Therefore, for the purposes of this study, the researchers used all these and randomly selected 26 of the up-to-34 dissertations available from the other cohorts, for a total of 104 dissertations from a population total of 126 . The populations included spring, summer, and fall graduates for each year, as provided by the university's Office of Records.

To keep the size of the study manageable, the researchers investigated the first 30 citations for each dissertation. Bibliographic citations of the same resource, whether because the student created duplicate entries or because the student cited multiple papers from conference proceedings, were included only once per dissertation. References to newspapers, popular magazines, class notes, and personal communications were excluded. Unpublished works on their way to publication (identified as being in press) also were excluded. In the event that one of the first 30 citations was excluded, we then incorporated citation number 31 to maintain a full complement of 30 from each dissertation. No dissertation contained fewer than 30 qualifying citations.

In order to track the results of this citation analysis, the researchers created an electronic spreadsheet that recorded an identification number for each dissertation, its date of completion and the department from which it emanated. For each bibliographic citation, the work's format was identified (and categorized as books and monographs, journals, government documents, conference papers and proceedings, Web pages, or other) and additional details were recorded, such as date of publication, title, publisher, and whether or not the resource is held currently at the University of Texas at Austin, and if so, in which medium (paper, electronic, or both).

\section{User Survey}

The second component of this project, the user survey, involved contacting all doctorate recipients in the identified programs for the years specified and providing them with a seven-question survey that asked about their experience in using the UT Libraries for their doctoral research (See appendix.) The survey gathered no personal identification information other than departmental affiliation and year of graduation. The survey results provide basic information on the perceived value of UT Libraries' research collections for these disciplines and insight into the changes in perceived value over a five-year period. 


\section{Results of Bibliographic Citation Analysis}

Citation analysis of the four dissertation cohorts consisted of investigating 780 citations for each cohort (i.e., 30 acceptable citations for each of 26 dissertations from each of two years in two departments, for a total of 3,120 citations). Each citation yielded information on format of the resource, availability or ownership of the resource at the UT Libraries, title of the publication and its citation frequency, the media in which UT holds the resource, year of publication, the span of years between the date of publication and the dissertation's year of completion, and the publisher for the resource.

\section{Format}

The researchers grouped the format of cited materials into six categories as seen in table 1, ranging in frequency from journals (representing $51.0 \%$ of the citations across all four cohorts) down to a miniscule 0.7 percent for Web pages. Government documents included the publications of various cooperative agencies that mingle university, state, and federal entities. Other documents included pamphlets, audio or visual materials, and reports not placed within government documents or some other category. Table 2 breaks the results down further for each of the four cohorts.

Journals served as the primary source of bibliographic citations for each group of dissertations studied, ranging from 45.3 percent (CE 97) to 62.4 percent (EP 02) of the total. Books and monographs also retained the second position for format of choice, ranging from 17.9 percent (CE 97) to 41.4 percent (EP 97) of the total for each cohort. CE students relied more heavily on government documents (12.2\%) and conference papers and proceedings $(9.6 \%)$ than did EP students $(0.5 \%$ and $1.9 \%$, respectively). Differences between the disciplines are notable within the theses/dissertations category as well, with 0.4 percent of $\mathrm{EP}(02)$ citations fitting this category and 5.3 percent of $C E(02)$ refer- encing dissertations or theses. Web page citations were nonexistent in 1997 CE dissertations, appeared in just one $1997 \mathrm{EP}$ dissertation, but increased significantly to 16 for 2002 CE dissertations, whereas 2002 EP dissertations recorded a more modest increase of 5 citations.

Within each discipline, format use remained consistent for the years studied, with the exception of EP students' use of journals and books/monographs for their dissertations. In 1997, EP students used journals for 50.4 percent of their citations, but in 2002, that number increased to 62.4 percent with their dependence on books and monographs dropping from 41.4 to 33.7 percent.

\section{Availability}

Availability of the resources cited in dissertation bibliographies from each of the four cohorts was investigated through use of the UT Libraries home page, found at http://www.lib.utexas.edu. In particular, the existence of the resource, and more specifically the actual volume or issue noted in the bibliography, as recorded in the libraries' NetCat, or online catalog, was considered indication that the material could have been accessed through the UT Libraries system. A clear limitation of this method, however, is that the researchers had access only to the current catalog, not to a retrospective catalog as it existed in 1997, or even 2002. A total

\begin{tabular}{|l|c|}
\hline \multicolumn{2}{|c|}{ TABLE 1 } \\
Percentage of Citations by Category \\
\hline \hline \multicolumn{1}{|c|}{ Type of Citation } & $\begin{array}{c}\text { Percentage of } \\
\text { Citations }\end{array}$ \\
\hline Journals & 51.0 \\
\hline Books and monographs & 27.9 \\
\hline Government documents & 6.4 \\
\hline $\begin{array}{l}\text { Conference papers and } \\
\text { proceedings }\end{array}$ & 5.8 \\
\hline Other documents & 5.4 \\
\hline Theses/dissertations & 2.9 \\
\hline Web pages & 0.7 \\
\hline
\end{tabular}




\begin{tabular}{|c|c|c|c|c|}
\hline \multicolumn{5}{|c|}{$\begin{array}{c}\text { TABLE } 2 \\
\text { Format of Citation Titles }\end{array}$} \\
\hline Format & Year & $\begin{array}{l}\text { Civ. } \\
\text { Eng. }\end{array}$ & $\begin{array}{l}\text { Ed. } \\
\text { Psych. }\end{array}$ & Grand Total \\
\hline \multirow[t]{2}{*}{ Journals } & 1997 & 353 & 393 & 746 \\
\hline & 2002 & 358 & 487 & 845 \\
\hline Journals total & & 711 & 880 & 1,591 \\
\hline \multirow[t]{2}{*}{ Books and monographs } & 1997 & 140 & 323 & 463 \\
\hline & 2002 & 145 & 263 & 408 \\
\hline Books and monographs total & & 285 & 586 & 871 \\
\hline \multirow[t]{2}{*}{ Government documents } & 1997 & 105 & 7 & 112 \\
\hline & 2002 & 86 & 1 & 87 \\
\hline Government documents total & & 191 & 8 & 199 \\
\hline \multirow[t]{2}{*}{ Conference papers and proceedings } & 1997 & 79 & 10 & 89 \\
\hline & 2002 & 71 & 20 & 91 \\
\hline $\begin{array}{l}\text { Conference papers and } \\
\text { proceedings total }\end{array}$ & & 150 & 30 & 180 \\
\hline \multirow[t]{2}{*}{ Other } & 1997 & 68 & 35 & 103 \\
\hline & 2002 & 63 & 1 & 64 \\
\hline Other total & & 131 & 36 & 167 \\
\hline \multirow[t]{2}{*}{ Theses/dissertations } & 1997 & 35 & 11 & 46 \\
\hline & 2002 & 41 & 3 & 44 \\
\hline Theses/dissertations total & & 76 & 14 & 90 \\
\hline \multirow[t]{2}{*}{ Web pages } & 1997 & & 1 & 1 \\
\hline & 2002 & 16 & 5 & 21 \\
\hline Web pages total & & 16 & 6 & 22 \\
\hline Grand total & & 1,560 & 1,560 & 3,120 \\
\hline
\end{tabular}

of 22.0 percent of resources cited do not appear in NetCat, implying that at least one in five resources used in the dissertation bibliographic citations investigated was not supported by the UT research collection.

\section{Frequency of Title Citation}

A total of 2,033 titles were represented by the 3,120 citations in this study, of which 25 titles were cited ten or more times, as can be seen in table 3 . This group of 25 titles represents 483 individual citations (187 from CE and 296 from EP), or 15.5 percent of the total citations. At the opposite end of the frequency scale, more than half the total citations $(54.6 \%$, or 1,704 ) come from titles that appear just once in this study. These numbers vary substantially from a study published in 1969, which concluded that 80 percent of citations came from 20 percent of the journals, according to Richard Trueswell's $80 / 20$ rule..$^{25}$ The numbers are consistent, however, with a 1993 study of psychology theses at California State University, Long Beach, which found that 80 percent of 7,797 citations in their study came from 80 percent of the 1,050 journals cited. ${ }^{26}$

Electronic versus paper resources

Citation of resources in 1997 and 2002 
that appear in the 2004 UT NetCat catalog only in paper or only in electronic media, or those that appear in both, identifies further distinctions between cohorts. (See figure 1.) Of the total citations, 59.4 percent are held today by the UT Libraries in only a paper medium, whereas 16.5 percent appear in both paper and electronic media and 2.1 percent are only electronic. Figure 1 represents these findings, indicating that substantially more of the resources used by EP students were accessible in paper-based resources, $(67.2$ percent compared with 51.6 percent for CE students). Among the four cohorts, resources cited that are available in both formats (today) ranged from 15.8 to 18.2 percent, demonstrating modest increases from 1997 to 2002 (2.2\% increase for CE and $0.2 \%$ for EP). A somewhat larger increase was evident in the use of electronic-only media in this five-year span, 4.4 percent for $\mathrm{CE}$ and 2.7 percent for EP. These numbers do not indicate a substantial shift toward digitizing paper resources, as might have been expected during this period.

\section{Age Span}

The average span of time between dates of publication for resources cited in dissertations and the dissertations themselves was fairly stable for each of the four cohorts, ranging from 11.3 years (EP97) to 13.7 years (EP02), as shown in figure 2 . When the researchers plotted the data, it became clear that the concentration of citations is weighted heavily within the span of twenty years preceding the dissertation's completion. These findings contrast with those of Bluma C. Peritz and Dina Sor who, in 1990, observed that "psychological research makes fairly extensive use of material that is at least 20 years old." 27

\section{Publishers}

Citation analysis data revealed a wide distribution of 


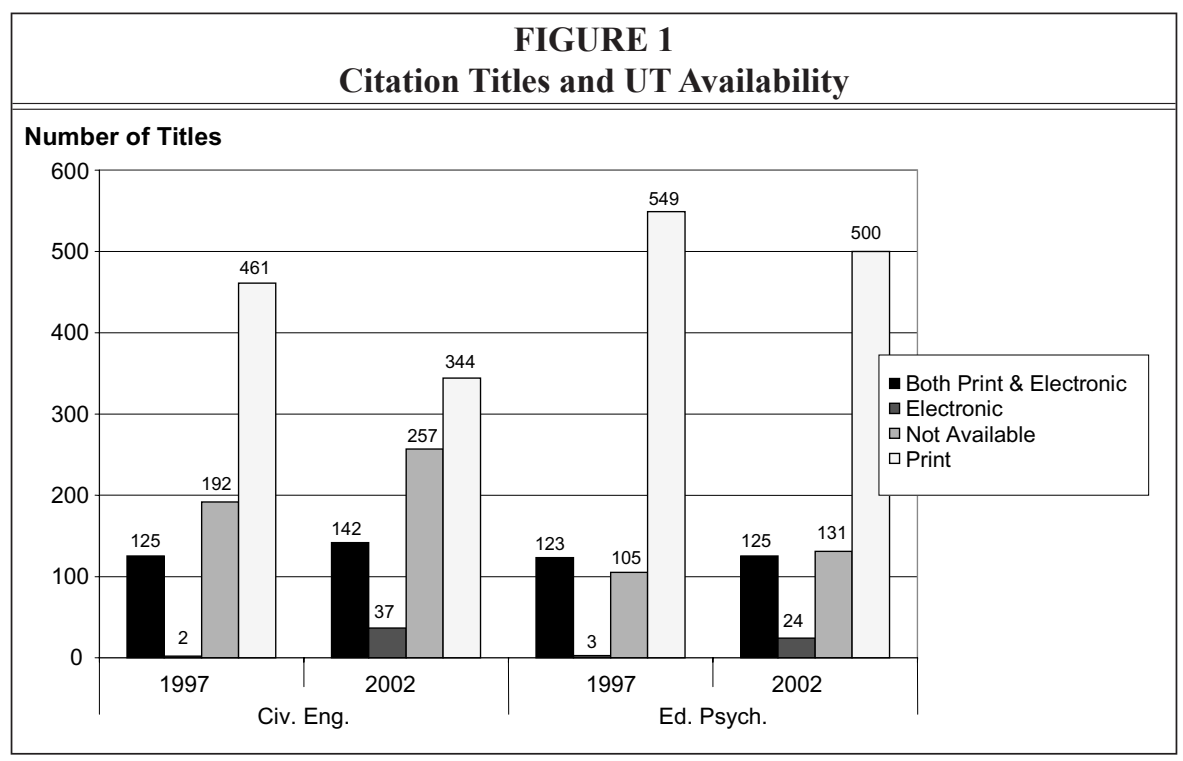

publishers in each discipline. There were 742 total publishers: 363 in civil engineering and 379 in educational psychology. The 363 publishers of $C E$ reference sources were associated with 1,475 citations, and the 379 publishers of EP resources were associated with 1,533 citations. Incomplete citations precluded identifying publisher information for the remaining citations from each cohort. As shown in table 4, there was one overwhelming publisher in each academic discipline. The American Society of Civil Engineers accounted for $124(8.4 \%)$ of the total number of CE citations, and the American Psychological Association accounted for 248 (16.2\%) of

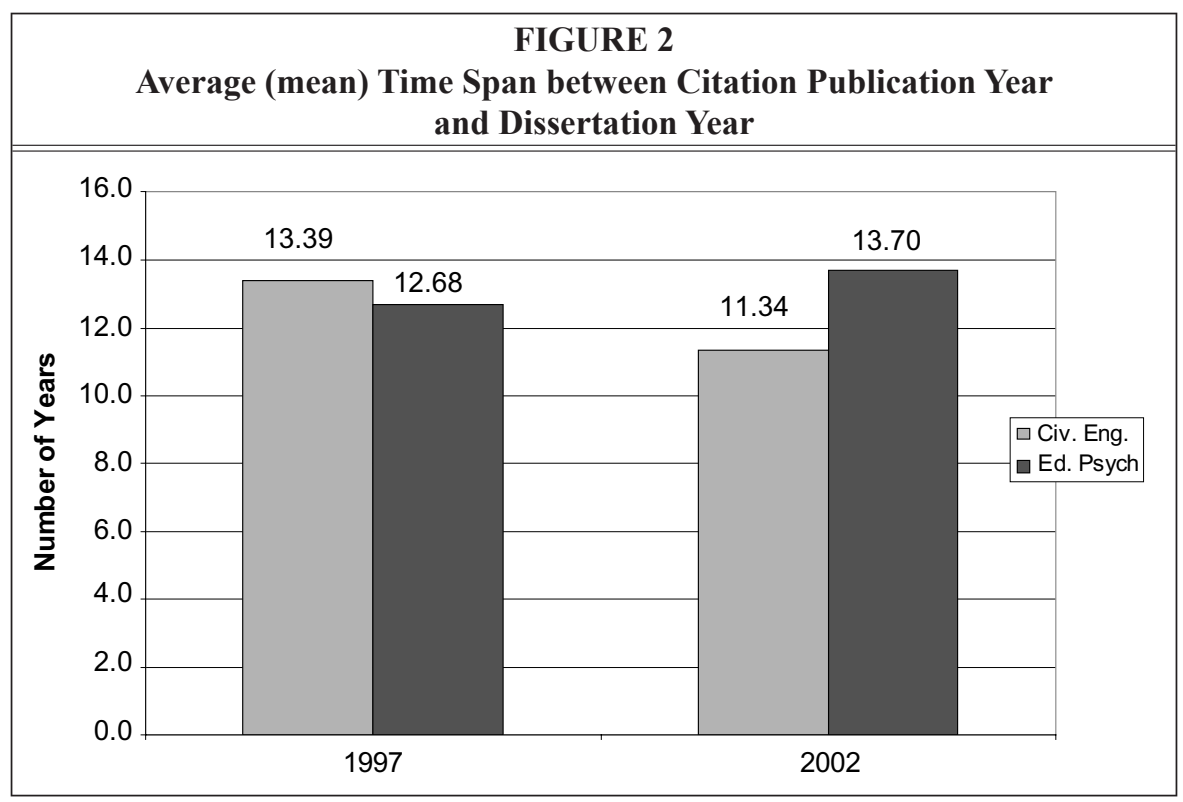


the total EP citations. Further analysis demonstrated that 37.0 percent (546) of the CE citations were published by the top ten publishers in the field, as identified in this study, and 41.0 percent (628) of EP citations were published by the top ten publishers in that field.

\section{Results of User Survey}

Had the researchers decided to conduct only a traditional citation analysis, the project would have ended at this point. They would have gathered some data on availability of resources but would be required to make serious leaps of inference regarding a reasonable course of action for the UT Libraries. However, the researchers believed that a user survey to explore awareness of information-seeking behavior would give more substance to the numbers collected from the bibliographic citation analysis.

Out of a population of 126 possible doctorate recipients in the fields of educational psychology and civil engineering in 1997 and 2002, the researchers received current mailing addresses for 116; thus this became the study population for the user survey. Six requests were returned as undeliverable mail; 44 surveys were completed for a 40.0 percent

\begin{tabular}{|l|c|}
\hline \multicolumn{2}{|c|}{$\begin{array}{c}\text { TABLE 4 } \\
\text { Engineering and Educational Psychology }\end{array}$} \\
\hline \hline Civil Engineering & \\
\hline American Society of Civil Engineers & 124 \\
\hline University of Texas, Austin & 61 \\
\hline Transportation Research Board & 56 \\
\hline Pergamon Press & 56 \\
\hline Construction Industry Institute & 50 \\
\hline John Wiley and Sons & 48 \\
\hline American Chemical Society & 41 \\
\hline American Concrete Institute & 40 \\
\hline Elsevier & 36 \\
\hline American Society for Testing Materials & 34 \\
\hline & \\
\hline Educational Psychology & \\
\hline American Psychological Association & 248 \\
\hline Sage Publications & 62 \\
\hline Plenum Press & 57 \\
\hline Lawrence Erlbaum Associates & 52 \\
\hline Academic Press & 50 \\
\hline Pergamon Press & 41 \\
\hline American Psychiatric Association & 35 \\
\hline Cambridge University Press & 26 \\
\hline Guilford Press & 34 \\
\hline John Wiley and Sons & \\
\hline & \\
\hline
\end{tabular}
return rate: 4 from $1997 \mathrm{CE}$ graduates, 13 from 2002 CE graduates, 8 from $1997 \mathrm{EP}$ graduates, and 17 from 2002 EP graduates. (Two surveys were unidentifiable by department and year.) Because only 12 surveys were returned from those who graduated in 1997, the researchers chose to analyze these survey data according to departmental affiliation only. (The surprisingly small change in use of electronic resources from 1997 to 2002 further justifies this decision.). (See table 5.)

\section{Utility and Accessibility of Collection}

Of the 43 participants who answered the question about the collection's utility,

nearly all (90.7\%) found the UT Libraries' collection moderately to very useful for researching and writing their dissertations, not surprising for a top-ten-ranked research library with more than 8.4 million volumes. Similarly, of 43 participants who chose to answer the question about the collection's accessibility, nearly all (90.7\%) found the UT Libraries' collection moderately to very accessible for researching and writing their dissertations. Even more interesting, however, is what the graduates chose to reveal about their information-seeking behavior through optional written comments. One 2002 EP graduate wrote, "Almost all books/periodicals required were owned by UT." 


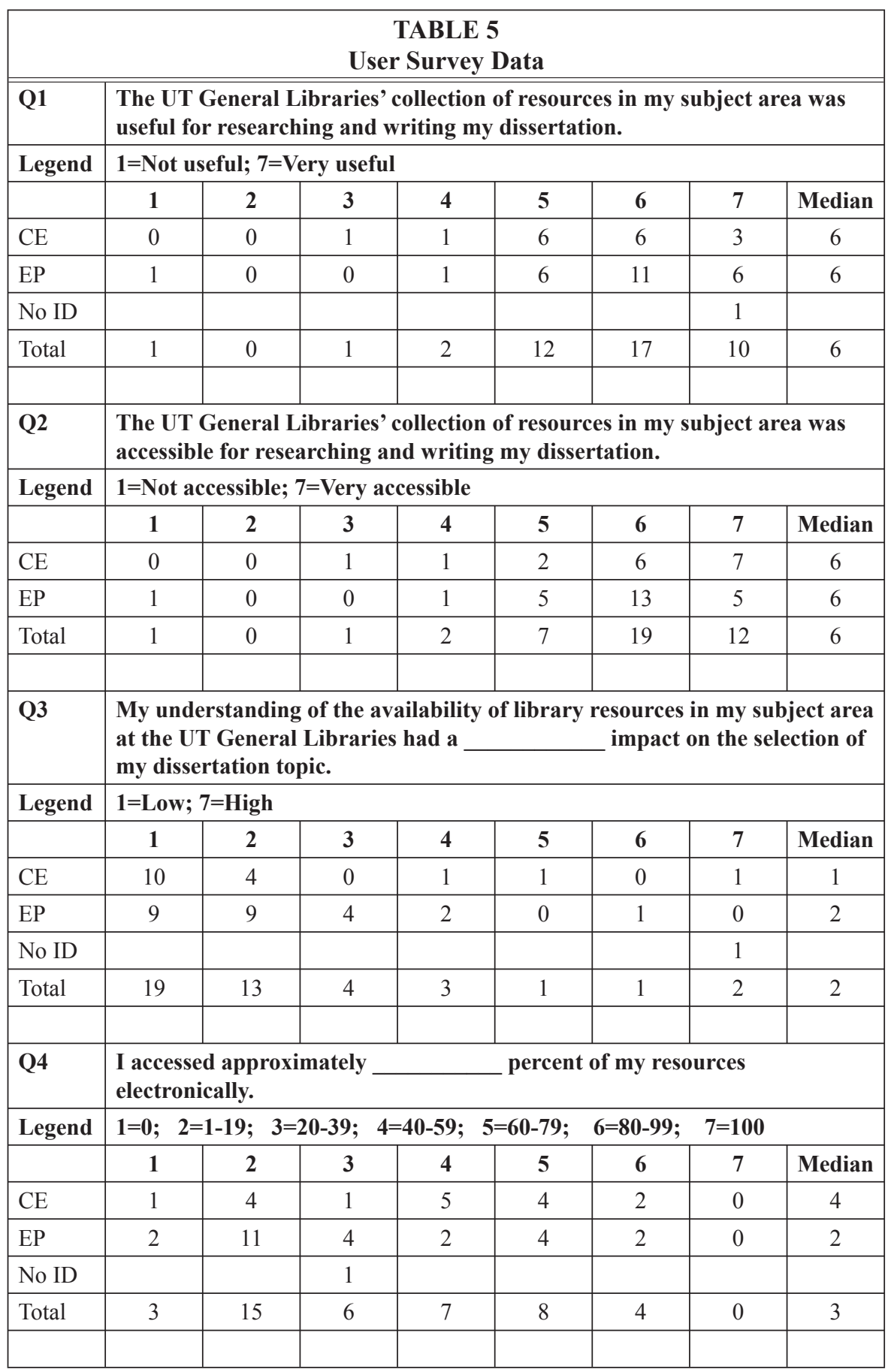




\begin{tabular}{|c|c|c|c|c|c|c|c|c|c|}
\hline & & & $\begin{array}{r}1 \\
\text { User }\end{array}$ & $\begin{array}{l}\text { BLF } \\
\text { rve }\end{array}$ & & & & & \\
\hline Q5 & $\begin{array}{l}\text { I use } \\
\text { resea }\end{array}$ & $\begin{array}{l}\text { library } \\
r \text { my dis }\end{array}$ & $\begin{array}{l}\text { servi } \\
\text { ation. }\end{array}$ & fro & & $\mathbf{G e}$ & ral L & ies w & ile doing \\
\hline Legend & $1=Y e$ & & & & & & & & \\
\hline & 1 & 2 & & & & & & & Median \\
\hline $\mathrm{CE}$ & 13 & 4 & & & & & & & 1 \\
\hline EP & 20 & 5 & & & & & & & 1 \\
\hline No ID & 1 & & & & & & & & \\
\hline Total & 34 & 9 & & & & & & & 1 \\
\hline & & & & & & & & & \\
\hline Q6 & Inter & loan w & seful & con & ctin & ny $r$ & earch & & \\
\hline Legend & $1=\mathrm{No}$ & $\mathrm{Il} ; 2=\mathrm{Ve}$ & seful & & & & & & \\
\hline & 1 & 2 & & 4 & & & 6 & 7 & Median \\
\hline $\mathrm{CE}$ & 0 & 0 & & 3 & & & 2 & 7 & 6.5 \\
\hline EP & 0 & 1 & 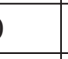 & 4 & & & 3 & 11 & 7 \\
\hline No ID & & & & & & & & 1 & \\
\hline Total & 0 & 1 & . & 7 & & & 5 & 19 & 7 \\
\hline Q7 & $\begin{array}{l}\text { I use } \\
\text { in or }\end{array}$ & $\begin{array}{l}\text { ollowing } \\
\text { m most }\end{array}$ & $\begin{array}{l}\text { ource } \\
\text { ortan }\end{array}$ & 1) to & ast & $\begin{array}{l}\text { y di } \\
\text { oort } \\
\end{array}$ & $\begin{array}{l}\text { rtati } \\
\text { t/val }\end{array}$ & (5). & , ranked \\
\hline & & & 1 & 2 & 3 & 4 & 5 & & Median \\
\hline UT Gen & ral Lib & $\mathrm{CE}$ & 5 & 3 & 9 & 0 & 0 & & 3 \\
\hline UT Gen & eral Lib & $\mathrm{EP}$ & 15 & 7 & 1 & 1 & 1 & & 1 \\
\hline UT Gen & $\mathrm{ral} \mathrm{Lib}$ & No ID & & 1 & & & & & \\
\hline UT Gen & $\mathrm{ral} \mathrm{Lib}$ & Total & 20 & 11 & 10 & 1 & 1 & & 2 \\
\hline Interlibr & ary Loa & & 2 & 3 & 2 & 6 & 4 & & 4 \\
\hline Interlibr & ary Loa & & 2 & 8 & 7 & 4 & 3 & & 2 \\
\hline Interlibr & ary Loa & & & & 1 & & & & \\
\hline Interlibr & ary Loa & & 4 & 11 & 10 & 10 & 7 & & 3 \\
\hline Colleagr & Ies - CE & & 4 & 7 & 1 & 4 & 1 & & 2 \\
\hline Colleagu & Ies - EP & & 3 & 5 & 10 & 4 & 2 & & 3 \\
\hline Colleagr & es - No & & 1 & & & & & & \\
\hline Colleagr & Ies - To & & 8 & 12 & 11 & 8 & 3 & & 3 \\
\hline Departm & ental li & - CE & 4 & 4 & 2 & 3 & 3 & & 2.5 \\
\hline Departm & ental li & - EP & 1 & 2 & 4 & 7 & 9 & & 4 \\
\hline Departm & ental li & - No ID & & & & & 1 & & \\
\hline Departm & ental li & - Total & 5 & 6 & 6 & 10 & 13 & & 4 \\
\hline
\end{tabular}




\begin{tabular}{|l|c|c|c|c|c|c|c|c|}
\hline \multicolumn{7}{|c|}{ TABLE 5 } \\
User Survey Data (continued) \\
\hline \hline Other - CE & 2 & 0 & 2 & 2 & 10 & & 5 \\
\hline Other - EP & 4 & 1 & 2 & 4 & 10 & & & 4 \\
\hline Other - No ID & & & & 1 & & & & \\
\hline Other - Total & 6 & 1 & 4 & 7 & 20 & & & 5 \\
\hline
\end{tabular}

A 2002 CE graduate wrote, "Most of my references are from conferences which UT General Libraries usually don't have." Although an initial reading of this comment might appear to express disappointment in the collection, couching it, instead, within the information-seeking behavior of engineering doctoral students reveals something different. This anecdote differs from the research of Gloria J. Leckie, Karen E. Pettigrew, and Christian Sylvain who found that when engineers consult written sources, they prefer technical reports and trade journals to scholarly books, journals, and conference papers. ${ }^{28}$ The changes in information-seeking behavior from doctoral student to practicing professional in the field of engineering are notable.

Several students commented on the convenience of the collection when they had access to online databases and online journals from home. One 2002 CE graduate wrote, "I could find the material either in hard copy or digital format ... most of the time." An EP graduate wrote, "In the uncommon event UT did not have the required resource immediately available, they worked w[ith] me to find/acquire the materials." In contrast, another 2002 EP graduate stated that he or she had to visit three libraries on campus to conduct research, indicating a degree of discomfort with the experience of visiting multiple repositories. Based on the citation analysis alone, the researchers concluded that from 1997 to 2002, the UT Libraries did a good job of providing resources for the EP and CE programs. The results implied that the ramp up of the use of digital resources was not steep. Supplemented with these survey data, however, the researchers were able to advise the libraries about a need for more education on available resources in all formats to enable all students (including doctoral students) to become more effective library users. Here is an example of a finding that a traditional citation analysis alone would not have revealed.

\section{Selection of Dissertation Topic}

Of the 43 participants who answered this question, most $(83.7 \%)$ chose their dissertation topic with no to little regard for the availability of library resources at UT. Just 9.3 percent of participants chose their dissertation topic with moderate to high regard for the availability of UT's library resources, and even fewer respondents $(7.0 \%)$ were neutral. These results are replicated within each department. Several 2002 CE graduates wrote that their dissertation topic was determined by research project needs, their advisor, or the availability of a research grant and, according to one participant, "had nothing to do with the library." One 2002 CE graduate expressed the situation quite succinctly: "Money equals a topic in engineering." A 2002 EP graduate selected a dissertation topic via personal interest "and did not consider library resources in that decision." Another 2002 EP graduate expressed regret that he or she was not "ever given a 'proper' introduction to the resources available."

\section{Electronic Resources}

Of the 43 participants who chose to answer this question, half (55.8\%) indicated that they accessed one-third or fewer of their research materials electronically. Over a quarter of the respondents $(27.9 \%)$ 
accessed approximately two-thirds or more of their research materials electronically, and $7(16.3 \%)$ indicated that they accessed between one-third and two-thirds of their resources electronically. No one reported accessing all resources electronically, but three participants indicated that they accessed none of their resources electronically.

When the responses to this question are analyzed according to departmental affiliation, some differences appear. Among CE graduates, there was a nearly equal distribution of responses into thirds: one-third of the graduates accessed approximately one-third or fewer of their resources electronically, one-third accessed between one-third and two-thirds of their resources electronically, and one-third of the CE graduates reported to have accessed two-thirds or more of their resources electronically. However, this is not the case with responses from EP participants. Seventeen EP respondents $(68.0 \%)$ indicated that they accessed approximately one-third or fewer of their resources electronically. In general, two-thirds of the total number of respondents accessed two-thirds or fewer of their resources electronically. The difference between the two departments, however, is striking.

Respondents also provided brief vignettes of the experience of users trying to acquire information in today's hybrid (print/electronic) libraries. Although one 2002 EP graduate emphasized that electronic access was a "terrific resource," another expressed a common sentiment: "I don't like to read stuff from a computer screen." Another 2002 CE graduate wrote about her or his changing approach to academic research: "Early on, I used mainly hard copies. Last 1.5 years it was online exclusively."

\section{Interlibrary Loan Services}

Of the 43 participants who answered this question, most $(79.1 \%)$ used interlibrary loan (ILL) services while doing research for their dissertation. Of 36 respondents who chose to gauge the utility of ILL services, three-quarters found the services to be moderately to very useful. Nearly identical results are found according to departmental affiliation.

Three 2002 EP graduates and one 2002 CE graduate described their perceptions of the value of ILL services for their research needs in quite positive terms: "Impossible without ILL's help. The staff was extremely helpful;" "Crucial. I needed materials from journals not published in Europe or North America and they were able to deliver"; "Extremely useful, efficient, dependable. Got many obscure resources. Not sure I could have completed research without it"; "I used the ILL service only a few times, mainly to supplement the material I could already find at UT." This is the sort of detail that could not be revealed by a citation analysis. For most researchers, ILL is a crucial service.

\section{Ranked Resources}

Participants were asked to rank five resources (UT General Libraries, ILL, colleagues, departmental libraries, other institutions) in order of importance and/ or value for conducting their dissertation research. Although each respondent did not necessarily rank each resource, the results reveal interesting details about the information-seeking behavior of each group of graduates.

When analyzed only according to number of votes for most valuable resource, the UT General Libraries comes in first with 46.5 percent of the first-place votes, colleagues is next with 18.6 percent of the votes, followed by other institutions $(13.9 \%)$, departmental libraries (11.6\%), and ILL $(9.3 \%)$. When analyzed according to average (mean) median score as displayed in table 5 , the results are not quite so overwhelming. (Although calculating means implies, incorrectly, that these rankings represent an interval scale instead of just an ordinal scale, the resultant means, if considered only by their rank order rather than making inferences about 
the size of the differences, are revealing.) UT General Libraries did earn the best average median score of 1.9. Colleagues is still next with an average median score of 2.7. ILL (which came in last among first-place votes) had an average median of 3.1. Departmental libraries had an average median of 3.5, and other institutions, which came in as the third-best among first-place votes, had an average median of 3.9. These differences can be explained when departmental association is taken into account.

EP graduates ranked the following resources according to most votes for firstplace rank: UT General Libraries (60.0\% of the first-place votes), other institutions (16.0\% of the votes), colleagues $(12.0 \%)$, ILL $(8.0 \%)$, and departmental libraries $(4.0 \%)$. By an overwhelming number of votes, the UT General Libraries ranks as the most important resource for EP graduates. CE graduates ranked the first-place resources this way: UT General Libraries (29.4\% of the first-place votes), colleagues and departmental libraries (tied with $23.5 \%$ of the votes each), and ILL and other institutions (tied with $11.8 \%$ of the votes each). There is no overwhelming winner as far as CE graduates are concerned. In fact, UT General Libraries, colleagues, and departmental libraries are almost in a three-way tie for most important resource. In addition, far fewer CE graduates than EP graduates are represented, rendering the collective firstplace vote winner more representative of EP respondent views.

When analyzed according to median score by department, the results change yet again. Rankings of average (mean) median scores for the resources as assigned by EP graduates are: UT General Libraries (1.6), colleagues (2.88), ILL (2.92) (additional significant digit added for emphasis), other institutions (3.7), and departmental libraries (3.9). Rankings of average median scores as assigned by $\mathrm{CE}$ graduates are: UT General Libraries (2.2), colleagues (2.5), departmental libraries (2.8), ILL (3.4), and other institutions
(4.1). These results from CE concur with those of Leckie, Pettigrew, and Sylvain, who state that engineers rely more on colleagues and internal sources of information than on repositories outside their own organization. ${ }^{29}$ The other institutions recorded varied widely from other university libraries in the United States (e.g., University of Pittsburgh, University of Michigan at Ann Arbor, University of Denver) to government-sponsored offices (e.g., Federal Aviation Administration, Texas Department of Health, and Texas Department of Transportation).

\section{Comparisons}

In comparing the results of the user study, which provided qualitative and behavioral data on library usage and perceived utility, with the results of the dissertation citation analysis, which provided observable data on collection usage, several interesting trends emerge that support the value of conducting a citation analysis enhanced by adding a behavior-based user survey.

\section{Perceived and Actual Value of UT \\ Libraries' Resources}

In contrasting the results of these studies, the researchers noted with interest that 60.0 percent of the EP respondents ranked the libraries as the most significant resource for their dissertation research, which corresponds well with the data that 84.9 percent of their citation sources are held by UT Libraries. In comparison, 29.4 percent of CE respondents ranked the libraries as their primary research resource, yet 71.2 percent of their citation sources are held by the UT Libraries. When questioned about the value of the libraries, 71.4 percent of CE cohorts and 76.2 percent of EP cohorts identified the UT Libraries' collection in their respective subject areas as useful to very useful for researching and writing their dissertations. Similarly, 88.2 percent of CE cohorts and 92.0 percent of EP cohorts indicated that the UT collections were accessible to very accessible. Nevertheless, the survey 
indicated a strong preference by CE students for acquiring their research materials from nonlibrary sources. Although the information-seeking behavior literature corroborates these findings, an important service choice for the UT Libraries in supporting engineering student research may be to arrange access options for students to ensure that materials not owned or acquired by UT are available from nearby agencies when needed by UT students.

\section{Perceived and Actual Use of Electronic Materials}

The researchers found that 18.6 percent (581) of the total bibliographic citations investigated for this study are available to users at the UT Austin Libraries in either electronic or electronic and print media. More precisely, 19.6 percent (306) of CE citations and 17.6 percent (275) of EP citations are available in the abovementioned media. When the observed data are compared to the behavioral data for electronic resources, the survey results offer a different picture. As noted above, approximately half the respondents $(55.8 \%)$ indicated that they accessed onethird or fewer of their research materials electronically and the other half indicated greater usage of electronic resources. This results in an apparent, but intriguing, discrepancy between actual use of electronic materials, which is less than one in five, and perceived use of electronic resources, which implies higher usage. The Hawthorne effect in research states that the fact and knowledge of being studied leads to altered performance and could provide an explanation for this gap if self-reporting of electronic resource use is higher than citation analysis indicates simply because of the approbation accorded to digital and electronic resources today. Another explanation for the discrepancy could be that students use electronic resources extensively for initial research and review of their subjects and hence report heavy use, yet still rely most heavily on printformat resources for their final write-up and analysis. The variation between usage figures for electronic resources in self-reporting versus actual performance warrants additional study, as shifts in usage affect collection development decisions with long-lasting consequences for researchers.

\section{Perceived and Actual Use of Interlibrary Loan, Other Institutions, and Colleagues} Just over one-fifth, or 22.0 percent (685), of the total number of bibliographic citations investigated in the four research cohorts were unavailable in the UT Libraries. The results of the user survey imply how the dissertation authors located their nonUT research materials, whether because the resource was unavailable through the UT Libraries or because the authors simply preferred to access the materials elsewhere. The survey demonstrates that 79.1 percent (34) of the respondents used ILL services, with 9.5 percent of respondents stating that ILL was the primary source for their research materials. According to respondents, colleagues and other institutions provided needed access to research resources as well, with 19.0 percent and 15.8 percent ranking these as the primary source for their research. Given that ILL ranked behind colleagues and other institutions as the primary source for research materials suggests the very necessary supporting role such a service plays at a large research library. The finding also serves to underscore the importance of information-seeking behaviors that often turn first to internal, "known" sources of information, preferences that would have gone undetected without the survey data.

\section{Conclusions and Recommendations}

The authors gathered data on research collection utility through citation analysis and supplemented and contrasted the results with data gathered via a user survey on the perceived utility of the collection, thereby using two research avenues to drive toward a richness of analysis. As described in the examples above, the results of one approach can 
complement and illuminate those of the other, demonstrating the need to engage both measures in order to create a more complete understanding of research collection utility.

If just one investigative approach had been used to question the place or importance of ILL services in doctoral dissertation research, the conclusions might have been quite different. Had the authors conducted only a classic citation analysis, the data would have prompted the conclusion that one in five resources cited by doctoral students in our study likely came from ILL, simply because these resources were not available at UT. But the survey data indicated that colleagues and other libraries play a greater role in providing resources than had been anticipated. This finding fits neatly into the mentor-apprenticeship model of doctoral work, leading to the more reasonable conclusion that doctoral students might turn to colleagues and professors for assistance in gathering research materials not otherwise available on campus rather than to ILL. Though the role of ILL as a service provider may remain stable, ILL does have an opportunity to expand its service.

As noted earlier, the use of electronic resources appears to be greater from selfreporting than the actual figures from citation analysis indicate. Using only bibliographic citation data, we might conclude that approximately 20 percent of the resources used by CE and EP graduates were in electronic form. However, self-reporting by authors indicates that half the participants accessed one-third or more of their materials electronically. An integrated analysis, using a combination of data-gathering techniques, can help diminish the likelihood of drawing conclusions falsely.

\section{Study Qualifications and Suggestions for Further Research}

From the perspective of hindsight, the two research approaches could have been constructed to allow closer correlation of results, which would have increased the reliability of the data. Cross-over questions between the two data-gathering efforts would have made possible quantitative tests on the results and allowed for correlation of the data, which then would have accorded greater reliability to the information extracted as individual survey responses could be matched with behavioral data for citation use. Had identified individuals been surveyed rather than anonymous authors, behavioral, qualitative data could be correlated with the quantitative citation analysis for an intriguing perspective on informationseeking behavior.

Greater attention to definitions used in both approaches may have diminished misunderstandings by respondents on several survey questions as well as provided greater consistency in classifying the citations. Lack of clarity on the question of use of electronic resources may have drawn in and lumped together use of the library's electronic catalog, databases, and other tools for research with accessing journals, books, and dissertations electronically. Additionally, lack of definitional distinction ranking the most useful sources of research material, particularly with regard to the UT Libraries and departmental libraries categories, may have muddied the results for this question.

The researchers discovered some lack of conformity in study definitions that translated into variations in the database when combining citation spreadsheets prepared by two individuals. For the sake of data reliability, these definitions should be stronger. Titles and publishers were difficult to standardize as well.

With regard to ownership of the resource being cited, the researchers noted only whether the UT Libraries NetCat of 2004 indicated ownership of the specific volume or edition that was cited and the media in which that volume was held, if present. Clearly, the use of the current catalog to determine the presence and media of resources two to seven years 
ago is problematic. UT personnel stated that little retrospective collecting had occurred during this period and that the current catalog thus offered a reasonable approximation of resources present in previous years. Surely, however, an exception to this could be the appearance of resources in dual media, which may have been available only in paper at an earlier date, thus leading to an overestimation of the use of electronic media.

The curious results generated by averaging citation age for each cohort (results ranged from 11 to 13 years) warrant further investigation. The existing research design did not include any means of weighting the value or significance of each bibliographic citation in comparison with that of others. One-time citations ranked equally with those receiving heavy use throughout the dissertation as they were chosen simply by appearance within the first 30 applicable titles in the bibliography. Adding a layer of analysis that combines textual citation with bibliographic citation, ranking the value of each, could affect the mean age of citations used in the dissertations. The 2002 cohorts did not demonstrate use of substantially younger materials, as expected, based on the findings of Sullenger. ${ }^{30}$ Part of the explanation for this could be the phenomenon of courtesy citations.

Because the only contact information received from the University of Texas's Texas Exes alumni association was postal addresses, the researchers were unable to contact survey population via e-mail. Had survey recipients been given the opportunity to respond on paper or been directed to an online survey response site, the researchers believe that the response rate likely would have been greater, thus increasing the reliability of the data that was retrieved.

A valuable addition to this study would have been the comparison of titles not held by the University of Texas Libraries with those identified as the top-cited (and thus, core) journals in the Journal Citation Reports, of the Institute for Scientific Information,
Science Edition and Psychology Edition, particularly for the years 1997 and 2002. Just one title, Journal of Contemporary Psychotherapy, appeared in both years' "not present" lists, minimizing the concern that the UT Libraries are not supporting research adequately in the studied disciplines. Yet from the libraries' perspective, the data (retrieved through citation analysis that covers a span of years) could be reason enough to consider adding a title of enduring interest to the collection.

\section{Conclusion}

The results of this behavioral citation analysis study suggest that the UT Libraries might market existing research resources more effectively, as well as extend collections to meet the demands of users. Clearly, the research collection does match resources to the research interests of dissertation authors. Given that more than 50 percent of citations out of more than 3,000 come from titles cited just once among the 104 authors, UT has built a broad collection. Four out of five citations are accessible through UT. However, the perceived value of the UT Libraries as a research resource by our respondents from civil engineering, as noted above, indicated that they ranked the library as less valuable to their research than would be expected from these figures. This research encourages the UT Libraries to engage in more outreach to graduate students, perhaps through orientation training or increased presence of pathfinders or other educational resources on the graduate school's Web site for doctoral students.

Collection enhancement is an ongoing assignment for libraries, made challenging by the disparity between increasing costs of materials, expanded offering of materials, and limited funds for acquisitions. As demonstrated in this study, librarians can engage in collection evaluation using a number of data-gathering techniques to profile the efficacy of a collection as well as its perceived utility, and thus determine how best to respond to user needs. 


\section{Appendix: The User Survey}

Survey: Library Resource Utilization at UT-Austin General Libraries by Doctoral Students in Educational Psychology and Civil Engineering, 1997 \& 2002

Date:

Departmental Affiliation Date of Dissertation

Educational Psychology $\quad \square 1997$

$\square$ Civil Engineering $\quad \square 2002$

1. The UT General Libraries' collection of resources in my subject area was useful for researching and writing my dissertation.
1
3
4
(Not useful)
(Neutral)
6 (Very useful)

Comments:

2. The UT General Libraries' collection of resources in my subject area was accessible for researching and writing my dissertation.
12
3
4
5
6
7
(Not accessible)
(Neutral)
(Very accessible)

Comments:

3. My understanding of the availability of library resources in my subject area at the UT General Libraries had a impact on the selection of my dissertation topic.
1
2
3
4
5
6
7
(Low)
(Moderate)
(High)

Comments:

4. I accessed approximately percent of my resources electronically.

$\begin{array}{lllllll}0 & 1-19 & 20-39 & 40-59 & 60-79 & 80-99 & 100\end{array}$

Comments: 
5. I used Interlibrary Loan services from the UT General Libraries while doing research for my dissertation.

$\square$ Yes (If yes, proceed to Question \#6.)

$\square$ No (If no, proceed to Question \#7.)

6. Interlibrary loan was useful for conducting my research.

$\begin{array}{lrlrrr}1 & 2 & 3 & 4 & 5 & 6\end{array}$

Comments:

7. I used the following resources to carry out my dissertation research, ranked in order from most important/valuable (1) to least important/valuable (5).

UT General Libraries

Interlibrary loan

Colleagues (i.e., fellow students, faculty members)

Departmental libraries

Other institutions (please specify below)

Comments:

Thank you for your participation! 1

Please return survey by July 15, 2004 in the enclosed stamped envelope to: 1

ATTN: B. Fuchs and C. Thomsen 1

The University of Texas at Austin 1

School of Information 1

1 University Station D7000 1

Austin, TX 78712-0390 1 


\section{Notes}

1. G. Bonn, "Evaluation of the Collection," Library Trends 22 (1974): 265-304.

2. Martin Faigel, "Methods and Issues in Collection Evaluation Today," Library 1

Acquisitions, Practice and Theory 9 (1985): 21-35. 1

3. T. E. Nisonger, Collection Evaluation in Academic Libraries: A Literature Guide and Annotated Bibliography (Englewood, Colo.: Libraries Unlimited, 1992). 1993).

4. F. W. Lancaster, If You Want to Evaluate Your Library, $2^{\text {nd }}$ ed. (Champaign: Univ. of Illinois,

5. Joanna Tan Yeok Ching and K. R. Chennupati, "Collection Evaluation through Citation Analysis Techniques: A Case Study of the Ministry of Education, Singapore," Library Review 51, no.8 (2002): 398-405.

6. Margaret Sylvia, "Citation Analysis as an Unobtrusive Method for Journal Collection Evaluation Using Psychology Student Research Bibliographies," Collection Building 17, no.1 (1998): $20-28$.

7. Philip M. Davis, "Where to Spend Our E-journal Money? Defining a University Library's Core Collection through Citation Analysis," Portal: Libraries and the Academy 2, no.1 (2002): $155-66$.

8. Rose B. Okiy, "A Citation Analysis of Education Dissertations at the Delta State University, Abraka, Nigeria," Collection Building 22, no.4 (2003): 158-61.

9. Anne L. Buchanan and Jean-Pierre V. M. Herubel, "Profiling Ph.D. Dissertation Bibliographies: Serials and Collection Development in Political Science," Behavioral and Social Sciences Librarian 13, no.1 (1994): 2.

10. Elizabeth Pan, "Journal Citation as a Predictor of Journal Usage in Libraries," Collection Management 2 (spring 1978): 29-38.

11. Margaret Stieg Dalton and Laurie Charnigo, "Historians and Their Information Sources," College \& Research Libraries 65, no.5 (Sept. 2004): 402.

12. Marion L. Buzzard and Doris E. New, "Research Notes: An Investigation of Collection Support for Doctoral Research," College \& Research Libraries 44, no.6 Nov. 1983): 469-75.

13. Carlette Washington-Hoagland and Leo Clougherty, "Identifying the Resource and Service Needs of Graduate and Professional Students: The University of Iowa User Needs of Graduate Professional Series." Portal: Libraries and the Academy 2, no.1 (2002): 125-43.

14. William L. Emerson, "Adequacy of Engineering Resources for Doctoral Research in a University Library," College \& Research Libraries 18, no.6 (1957): 455-460, 504.

15. Joy Thomas, "Graduate Student Use of Journals: A Bibliometric Study of Psychology Theses," Behavioral \& Social Sciences Librarian 12, no.1 (1993): 1-7.

16. Lois Kuyper-Rushing, "Identifying Uniform Core Journal Titles for Music Libraries: A Dissertation Citation Study," College \& Research Libraries 60, no.2 (Mar. 1999): 153-63.

17. Laurel A. Haycock, "Citation Analysis of Education Dissertations for Collection Development," Library Resources \& Technical Services 48, no.2 (April 2004): 102-6.

18. Margaret Sylvia and Marcella Lesher, "What Journals Do Psychology Graduate Students Need? A Citation Analysis of Thesis References," College \& Research Libraries 56, no.4 (July 1995): 313-18.

19. Lois Bebout, Donald Davis Jr., and Donald Oehlerts, “User Studies in the Humanities: A Survey and a Proposal," RQ 15, no.1 (fall 1975): 40-44.

20. M. B. Line, "The Information Uses and Needs of Social Scientists: An Overview of INFROSS," Aslib Proceedings 23 (Aug. 1971): 412-34.

21. Paula Sullenger, "E-journals and Citation Patterns: Is It All Worth it?" Serials Librarian 44, no.3/4 (2003): 109-213.

22. For a recent study examining the impact of electronic resources on graduate student research behavior, see Erin T. Smith, "Assessing Collection Usefulness: An Investigation of Library Ownership of the Resources Graduate Students Use," College \& Research Libraries 64, no.5 (Sept. 2003): 344-55.

23. Bebout, Davis, and Oehlerts, "User Studies in the Humanities," 42.

24. See David Ellis, "Modeling the Information-seeking Patterns of Academic Researchers: A Grounded Theory Approach," Library Quarterly 63, no.4 (1993): 469-86, for a classic study. For information-seeking behavior of social scientists, see Lokman I. Meho and Helen R. Tibbo, "Modeling the Information-seeking Behavior of Social Scientists: Ellis's Study Revisited," Journal of the American Society for Information Science and Technology 54, no.6 (2003): 570-87. For information-seeking behavior of engineers, see Gloria J. Leckie, Karen E. Pettigrew, and Christian Sylvain, "Modeling the Information-seeking of Professionals: A General Model Derived from Research on Engineers, Health Care Professionals, and Lawyers," Library Quarterly 66, no.2 (1996): 161-93. 
25. Richard Trueswell, "Some Behavioral Patterns of Library Users: The 80/20 Rule," Wilson Library Bulletin 43 (1969): 458-61.

26. Thomas, "Graduate Student Use of Journals," 4.

27. Bluma C. Peritz and Dina Sor, "The Use of Libraries by Graduate Students in Psychology as Indicated by Citations," Collection Management 12, no.3-4 (1990): 11-23.

28. Leckie, Pettigrew, and Sylvain, "Modeling the Information-seeking of Professionals," 165.

29. Ibid.

30. Sullenger, "E-journals and Citation Patterns."

\section{Applications/Nominations Invited for C\&RL Editor}

Applications and nominations are invited for the position of editor of College \& Research Libraries (CERL), the bimonthly, scholarly research journal of the Association of College and Research Libraries (ACRL). The editor is appointed for a three-year term, which may be renewed for an additional three years. Applicants must be a member of ALA and ACRL. Qualifications include professional experience in academic libraries, a record of scholarly publication, editing experience, an ability to meet publication deadlines, an understanding of the scholarly communication process, and a broad knowledge of the issues confronting academic libraries.

Some funding for editorial assistance and travel to relevant conferences is available, and there is a small honorarium for the editor.
Appointment will be made by the ACRL Board of Directors at the 2007 Annual Conference upon the recommendation of the search committee and of the ACRL Publications Coordinating Committee. The incoming editor will serve for at least one year as editor-designate, working with the current editor, before assuming full responsibility for $C \mathcal{E} R L$ in July 2008.

Nominations or resumes and letters of application, including the names of three references, should be sent to:

C\&RL Search Committee c/o Dawn Mueller

ACRL Production Editor

50 East Huron Street

Chicago, IL 60611

e-mail:dmueller@ala.org

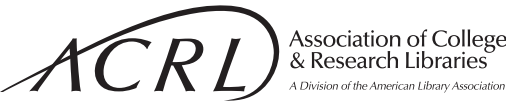

The deadline for receipt of applications is December 4, 2006. Finalists will be interviewed at the Midwinter Meeting in January 2007. 